\title{
Criatividade dentro da Educação: um estudo de caso do Curso de Administração da UFSC - Universidade Federal de Santa Catarina
}

\author{
Gabriela Cordioli Coto ${ }^{1}$ \\ Luís Moretto Neto ${ }^{2}$ \\ Andressa Saazaki Pacheco ${ }^{3}$
}

\begin{abstract}
Resumo
É incontestável a importância da criatividade na sociedade do conhecimento. Nesse processo de desenvolvimento criativo, já foi comprovado que tanto a família quanto a escola exercem papéis de suma importância. Diante disso, o presente artigo tem como objetivo identificar a contribuição do Curso de Administração da Universidade Federal de Santa Catarina para o estímulo da criatividade em seus alunos. O estudo foi delineado a partir da avaliação dos planos de ensino das disciplinas oferecidas pelo CAD - Departamento de Ciências da Administração e da análise da percepção dos alunos. Quanto à metodologia aplicada, o estudo caracterizou-se como: qualitativo, exploratório, descritivo, teórico aplicado, estudo de campo, documental, ex-post facto, participante e teórico aplicado. Dentre os resultados atingidos, identificou-se uma discrepância entre a avaliação dos planos de ensino (teoria) e a percepção dos alunos (prática), assim como uma real contribuição do curso para o estímulo da criatividade entre razoável e boa.
\end{abstract}

Palavras-chave: Criatividade. Inovação. Processo educacional.

\section{Introdução}

Constantemente, os indivíduos são expostos a situações desconhecidas que exigem respostas imediatas e originais como solução. Os padrões e esti-

\footnotetext{
${ }^{1}$ Graduada em Administração pela Universidade Federal de Santa Catarina. Tutora do curso de Adminitração a Distância da Universidade Federal de Santa Catarina. Endereço: Departamento de Ciências da Administração. Campus Universitário,Trindade, Florinópolis - SC. CEP: 88040-900. E-mail: gabi_ccoto@yahoo.com.br.

${ }^{2}$ Doutor em Engenharia de Produção pela Universidade Federal de Santa Catarina. Professor associado II do curso de Administração da Universidade Federal de Santa Catarina. Endereço: Departamento de Ciências da AdministraçãoCampus Universitário,Trindade, Florinópolis - SC. CEP: 88040900.E-mail:moretto@cse.ufsc.br.

${ }^{3}$ Mestrado em Administração pela Universidade Federal de Santa Catarina. Doutoranda em Engenharia e Gestão do Conhecimento pela Universidade Federal de Santa Catarina. Endereço: Rua Prof. Simão José Hess, nº 191/701 Florianópolis-SC. E-mail: andressa pacheco@hotmail.com. Artigo recebido em: 10/03/2009. Aceito em: 17/05/2009. Membro do Corpo Editorial Científico responsável pelo processo editorial: Emerson Antônio Maccari.
} 
los de vida da atualidade transformam-se muito rapidamente, fruto da criatividade e da materialização dos feitos, através de avanços tecnológicos.

$\mathrm{Na}$ era do conhecimento, o potencial inovador é apontado como uma habilidade de sobrevivência no mercado de trabalho, o qual é caracterizado por constantes mudanças. Nesse contexto, a tomada de decisão, dentro das organizações, assume proporções grandiosas e exige dos participantes desse processo conhecimentos e habilidades que possam antever o futuro e criar caminhos e possibilidades para a organização.

Em face desse cenário, é exigido dos gestores mais do que simplesmente conhecimentos adquiridos na academia ou na prática, é demandado também que eles tenham capacidade de empreender e de serem profissionais ágeis, inovadores e criativos.

A crescente demanda por criatividade nos ambientes organizacionais, nas últimas décadas, despertou em estudiosos da área o interesse pelo estudo de aspectos que estimulem o poder de criação do ser humano. Nesse processo, já é comprovado que tanto a família, quanto a escola exercem uma papel de extrema importância. Afinal, essas duas instituições são responsáveis pela formação do indivíduo e podem afetar negativamente ou positivamente no desenvolvimento do poder criativo.

Tendo em vista o cenário mutante enfrentado pelos profissionais de diferentes áreas, discute-se, no âmbito educacional, a importância do incentivo à criatividade dentro das instituições da área. O ensino da criatividade, segundo Virgulim et al. (2003), deve ser trabalhado por meio de adequação às propostas metodológicas, através de programas e treinamentos apropriados. Dessa forma, pode constituir uma ferramenta estratégica para potencializar habilidades e talentos humanos.

Os autores também sugerem algumas mudanças que se fazem necessárias no contexto educacional. Nessa atual conjuntura, caracterizada pela mudança e transição, a escola não pode apenas transmitir conteúdos com os olhos voltados para o passado. Não deve restringir-se a metodologias que enfatizam a memorização e aquisição de conhecimentos, negligenciando o aspecto formador, experimentador e criador do saber. É importante direcionar seu olhar para o futuro, exercitando a imaginação e a fantasia de seus alunos na tentativa de solucionar problemas e situações que novos tempos sempre trazem. É preciso atrelar o aprender ao prazer.

Torrance (1974) afirma que a tarefa de ensinar o pensamento criativo consiste em desenvolver nos alunos, entre outras coisas, as habilidades para 
perceberem lacunas, definirem problemas, coletarem e combinarem informações, elaborarem critérios para julgar e testar soluções, bem como elaborar planos para a implementação das soluções escolhidas.

Complementando essa ideia, Torre (2005) defende que a criatividade na educação não trata de incorporar novas técnicas, mas que essa forma de proceder seja criativa e promova a criatividade por seu paralelismo com o processo criativo. Trata-se de transferir o processo criativo ao de ensinar.

A importância de desenvolver atitudes e habilidades criativas, desde a educação infantil até a universidade, vem justificada pela necessidade de obter uma melhoria social continuada. Torre (2005, p. 146) preconiza que a "riqueza de um país não está apenas em seus recursos naturais, mas também na capacidade inovadora e criativa das gerações mais jovens".

Tendo em vista a formação de acadêmicos que venham suprir as necessidades do mercado de trabalho, o curso de graduação em administração da Universidade Federal de Santa Catarina tem como objetivo preparar seus alunos para serem profissionais criativos, com capacidades empreendedoras, capazes de se integrarem facilmente aos objetivos de uma organização e coordenarem, em qualquer ramo de atividade, as mais importantes estratégias operacionais.

Dentro dessa perspectiva, o presente artigo, embasado em estudo acadêmico realizado anteriormente, teve como intuito analisar a contribuição do Curso de Administração da Universidade Federal de Santa Catarina para o estímulo da criatividade nos alunos egressos do segundo semestre do ano de 2007.

\section{Revisão Bibliográfica}

A criatividade, durante anos, tem servido como objeto de estudo para diferentes disciplinas, como psicologia, sociologia, filosofia, história, antropologia, neurociências, administração, entre outras. Devido à complexidade do assunto, o tema será sistematizado em quatro etapas: criatividade; ambientes propícios à criatividade; e criatividade no processo educacional. Posteriormente, serão abordadas as competência essenciais aos administradores. 


\subsection{Criatividade}

Segundo a etimologia da palavra, criatividade está relacionada com o termo criar, do latim creare, que significa "dar existência, sair do nada, estabelecer relações até então não estabelecidas pelo universo do indivíduo, visando determinados fins" (PAROLIN, 2001). Estudos demonstram que criatividade é uma extensão da inteligência capaz de combinar os dados contidos no cérebro e obter algo novo e útil (VIRLULIM et al., 2006).

Torre (2005), em sua obra, afirma que a criatividade é um bem social, pois, segundo o autor, é através dessa capacidade humana que torna-se possível desenvolver uma sociedade. O autor também defende que o homem só chega à sua plena realização quando consegue ampliar ao máximo suas potencialidades. Sendo a criatividade a qualidade mais própria e específica do ser humano, é natural supor que o pleno desenvolvimento passe pela potencialização dessa qualidade.

No âmbito empresarial, a criatividade está intimamente relacionada com a produtividade, tendo em vista que o contexto atual do mercado está pautado nas inovações. Bono (2000) defende a existência de três grandes tendências organizacionais: 1) as organizações serão cada vez mais competentes em suas atividades; 2) a tecnologia não será fator de diferenciação; e 3) os valores extraídos das informações serão mais importantes do que as próprias informações. Diante dessa realidade, o autor afirma que o pensamento tradicional deve dar lugar à criatividade, ao pensamento construtivo e à capacidade de inovar.

De fato, graças às grandes mentes criativas, hoje a humanidade tem, à sua disposição, diversas invenções e tecnologias que facilitam - em muito - a vida do ser humano. O primeiro automóvel, meio de transporte mais utilizado na atualidade, foi desenvolvido em 1885, por Karl Friedrich Benz e Gottlieb Wihelm Daimler, os quais posteriormente fundiram suas empresas e criaram a Mercedes - Benz. O telefone, meio de comunicação indispensável atualmente, foi criado por Alexandre Graham Bell, em 1876. A caneta esferográfica, um objeto tão simples, mas também tão utilizado, foi inventada em 1937, pelo tipógrafo húngaro Ladislao Biro, quando procurava desenvolver uma caneta que não borrasse e a tinta não secasse no depósito. Outro objeto indispensável para o ser humano, a lâmpada, foi criada por Thomas Alva Edison, em 1879. A coca-cola, desenvolvida pelo farmacêutico Jonh Styth Pemberton, em 1886; a famosa boneca Barbie, desenhada por Ruth Handler, 
em 1959; o band-aid, inventado por Earl Dickson, em 1918, entre tantas outras invenções (DUARTE, 1997).

Para Carr (1997, p. 45), "Estimular a criatividade dentro das empresas significa encontrar soluções para problemas, sempre visando a (sic) otimização dos lucros". A criatividade nas organizações, bem como todas as práticas adotadas pela maioria delas tem sempre um fim calculado pela consequência.

Alencar (1996) reforça a importância da necessidade de estimular a inovação dentro das organizações. Segundo o autor, as empresas devem cada vez mais buscar o gerenciamento das pessoas de forma a promover a criatividade. Destaca ainda a importância da criatividade no aprimoramento da produtividade e da qualidade no trabalho.

Parolin (2001), mestre pela Universidade Federal do Rio Grande do Sul, realizou uma pesquisa com 189 líderes formais de empresas da Região Metropolitana de Curitiba e chegou a alguns resultados que demonstram a importância da criatividade na ótica desses entrevistados:

a) Desses líderes, $96 \%$ concordam que a criatividade pode melhorar a produtividade nas empresas;

b) $84 \%$ concordam que a criatividade está presente em todas as áreas de atuação do ser humano;

c) $86 \%$ concordam que a inovação depende da criatividade;

d) $82 \%$ admitem acreditar que a criatividade na empresa serve para minimizar o estresse individual e grupal;

e) $78 \%$ admitiram acreditar que "brincadeira não é coisa somente de criança" (ludicidade presente no processo criativo e nos ambientes de trabalho); e

f) $88 \%$ concordam que há lugar para atitudes inovadoras nas empresas.

O resultado dessa pesquisa contribuiu para desfazer a crença de que a criatividade está restrita a áreas de atuação do ser humano, distantes do ambiente organizacional, e aponta para a emergência de discussões mais aprofundadas em torno dos seus mecanismos, dos meios para sua obtenção e condução dentro das empresas.

O caminho mais seguro para a inovação é o desenvolvimento do conhecimento e da criatividade dentro da organização (DRUCKER, 1994). Está comprovado que o sucesso de um negócio depende, em grande parte, do conhecimento empresarial contido dentro da organização. E a educação 
empresarial, não só dos gestores, mas também dos funcionários, é prova de que o aporte de conhecimento é fator primordial para o crescimento das micro e pequenas empresas (SEBRAE, 2009).

De Masi (2005) afirma que trabalhadores mais cultos, especializados e escolarizados, estariam prontos para assumir tarefas que exigem criatividade, as quais, hoje, são desempenhadas por computadores.

Faz-se necessário, portanto, o estabelecimento de condições, dentro das organizações, para uma aprendizagem autogeradora, isto é, proporcionar um ambiente onde as pessoas que desejam ser criativas obtenham estímulos para desenvolver sua potencialidade. Para que isso ocorra, as empresas devem lançar mão de estratégias de gestão que proporcionem um ambiente propício ao estímulo e desenvolvimento de características criativas nos indivíduos.

\subsubsection{Ambientes propícios à criatividade}

A influência social na expressão da criatividade é inquestionável dentre os estudiosos do tema criatividade. Ray e Meyers (1996) acreditam que a criatividade precisa ser descoberta e desenvolvida, pois é algo inerente ao ser humano, é um estilo de vida a ser vivenciado e praticado. Segundo os autores, "cada indivíduo tem uma razão de ser, uma fusão particular de talentos e capacidades que podem guiá-lo à realização” (RAY; MEYERS, 1996, p. 184).

Alencar (1996) preconiza que a criatividade se desenvolve no contexto social e está relacionada com o processo de pensamento que tem origem na cultura. Esse processo recebe forte influência social por meio de normas, tradições, valores, tabus, sistemas de incentivo e punições.

No âmbito da Administração e dos negócios, o processo de criação também está intimamente relacionado ao estilo de vida, sustentam Ray e Meyers (1996). Na concepção dos autores, criatividade nos negócios é um processo contínuo, organizado, consciente e sensível, desenvolvido através de uma série de atitudes ao longo da vida da organização.

Paradoxalmente, Amabile (1999) estabelece seis categorias de práticas gerenciais que estimulam a criatividade: desafios, liberdade de expressão, recursos à disposição do profissional, características dos grupos de trabalho, encorajamento pela supervisão e apoio organizacional.

$\mathrm{Na}$ mesma linha de pensamento estabelecido pela autora, Alencar (1996) já identificara alguns fatores presentes no ambiente de trabalho que estimulam e inibem a criatividade em organizações. Dessa forma, foram 
estabelecidas 12 categorias que estimulam a criatividade: ambiente físico, comunicação, desafios, estrutura organizacional, liberdade e autonomia, participação na tomada de decisão, recursos tecnológicos e materiais, salários e benefícios, suporte da chefia, suporte do grupo de trabalho, suporte organizacional e treinamento.

Wechler (1998) também ressalta que um ambiente propício à liberação criativa promove a autorrealização individual, uma sociedade mais saudável, além de estimular ao máximo a capacidade humana para produzir inovações e propor alternativas, com maior grau de viabilidade, para os problemas. A autora define três tipos de variáveis influenciadoras da criatividade: as variáveis culturais, as perceptuais e as emocionais. Essas variáveis, em diversos casos, acabam se posicionando como barreiras ao processo de criação.

Dentre as barreiras culturais que impedem a manifestação da criatividade destacam-se: orientação para a estabilidade, punição ou exclusão do individuo que diverge da norma, valorização da lógica e descrédito da intuição, preferência pela tradição ao invés de mudanças, expectativa de comportamentos e atitudes que se alinham ao "papel sexual típico".

Quanto às barreiras perceptuais, as principais bloqueadoras à criatividade são: dificuldade de perceber ou ser sensível a problemas, busca de soluções rápidas e imediatas, pensamento rígido, inabilidade de ver problemas sob um novo enfoque, dificuldade de suspender julgamentos e críticas.

Por fim, as variáveis emocionais que podem servir como barreira à inovação são: medo do fracasso, de fazer algo diferente e da frustração, miopia para enxergar os próprios pontos fortes e qualidades, imaginação empobrecida, insegurança diante de situações desconhecidas e ambíguas, dificuldade de tolerar a desordem, receio de ser agressivo, de influenciar as outras pessoas e medo de perder o controle da situação.

Corroborando tal colocação, Terra (2000) identifica os seguintes fatores impeditivos para a criatividade: a pressão para se conformar, atitudes $e$ meios excessivamente autoritários, medo do ridículo, intolerância para com as atitudes mais joviais, excesso de ênfase nas recompensas e nos sucessos imediatos, busca excessiva de certeza, hostilidade para com as personalidades diferentes, falta de tempo para pensar e rigidez da organização.

Um exemplo de cultura organizacional que incentiva a criatividade é a empresa norte americana $3 \mathrm{M}$, conhecida mundialmente por promover constantemente a inovação e a criação. Dentre as políticas de incentivo à criação que são utilizadas pela 3M, estão: 
a) Ouvir todos que tenham uma ideia original, mesmo que, no primeiro momento, a mesma pareça absurda;

b) encorajar os funcionários sem se concentrar nos detalhes, pois são eles que devem desenvolver suas ideias;

c) contratar bons profissionais e dar-lhes liberdade e espaço para trabalhar e criar;

d) encorajar a imaginação experimental;

e) Estimular o pessoal técnico a gastar $15 \%$ de seu tempo com projetos próprios;

f) todas as divisões têm como meta ter $25 \%$ de suas receitas advindas de produtos com menos de cinco anos de idade;

g) premiações monetárias e não monetárias são distribuídas a funcionários que contribuírem com ações e ideias inovadoras; $e$

h) incentivos ao "entrepreneurship" mediante a possibilidade de os funcionários se tornarem sócios de negócios que eles começaram.

A 3M é conhecida mundialmente pelo incessante compromisso com a inovação e a criação de tecnologias e produtos. Pessoas, ao redor do mundo, procuram na $3 \mathrm{M}$ produtos e ideias que solucionem seus problemas $e$ tornem suas vidas mais fáceis e melhores. Com quase 50 mil produtos, mais de 40 plataformas tecnológicas e liderança nos maiores mercados do mundo, a 3M procura, por meio da cultura da criatividade, dentro da organização, desenvolver soluções geniais para as mais variadas necessidades (TERRA, 2000).

\subsubsection{Criatividade no Processo Educacional}

O processo criativo pode ser desenvolvido em várias áreas de atividade humana, seja nas ciências, nas artes, no trabalho ou na educação. Em razão do progresso e da complexidade humana, o interesse pela criatividade por seu desenvolvimento e consequente importância vem aumentando e é cada vez mais reconhecido.

Toren (apud ALENCAR, 1996) menciona quatro grupos de competências desejáveis em profissionais de distintas áreas: comportamentais (ter iniciativa), perceptuais (ser capaz de lidar com a informação de distintas pers- 
pectivas), afetivas (ter sintonia com outro) e simbólicas (habilidade de pensar de forma criativa). É sabido que as potencialidades criativas são desenvolvidas pelo indivíduo desde os primeiros anos de vida, porém é possível, por meio de estratégias, desenvolver um processo educacional criativo, que estimule e motive a criação e a inovação nos indivíduos (MARTíNEZ, 1997).

Mesmo diante do crescente reconhecimento da necessidade de uma educação que privilegie também a criatividade, persiste nos sistemas educacionais, de diferentes países, uma série de elementos que inibem o desenvolvimento e dificultam a expressão da capacidade de criar. Alencar (1996) afirma que é comum uma educação voltada excessivamente para o passado, com ênfase exagerada na reprodução do conhecimento e na memorização de ensinamentos, exigindo do aluno conhecimentos já ultrapassados. Afinal, o passado é uma referência e a educação é uma via para construção de um futuro novo e melhor para os entes envolvidos. Muitas vezes, na escola, aprende-se que cada problema ou questão tem apenas uma resposta certa, sendo a dicotomia do certo-errado fortalecida todo o tempo. O erro gera constrangimento e vergonha, o que leva à inibição da liberdade de expressão, da flexibilidade e, consequentemente, da criatividade.

Os autores reforçam que essa cultura educacional vem em contraposição com as exigências do mercado. Enquanto os tempos modernos exigem um perfil de homem marcado, sobretudo pela autoconfiança, pela iniciativa, pela independência de pensamento e ação, pela persistência, pela coragem para correr riscos e habilidades para resolver novos problemas, os traços mais cultivados em muitas escolas têm sido a obediência, a passividade e a dependência.

A escola, segundo Wechsler (1998), tem função de ensinar a pensar e isso pode ser feito através do desenvolvimento da criatividade e da motivação intrínseca de cada aluno e nunca por meio de reforço ou punição.

Visando aliar o processo criativo ao processo educacional, Torre (2005) elaborou um modelo composto por cinco etapas que devem estar presentes no sistema educacional: Problematizar, Climatizar, Estimular, Estimar e Orientar.

a) Problematizar - o processo criativo tende a iniciar-se com a conscientização de alguma situação problemática, com a insatisfação, com a tensão interna ou com a necessidade de expressar o próprio pensamento. Esses questionamentos levarão o indivíduo à 
busca. Portanto, o processo didático deverá levar o aluno a questionar-se e a interrogar-se para que desperte a sua curiosidade intelectual.

b) Climatizar - nesta etapa, o indivíduo está aparentemente despreocupado, porém interiormente procura as respostas para seus questionamentos. A atuação didática consiste em definir os pontos mais significativos ou relevantes e deixar que o aluno indague por si mesmo, que busque e reúna qualquer tipo de informação relacionada com o problema ou tema a ser estudado. O professor tem o papel de informar e Estimular um clima de comunicação e confiança que favoreça a busca e a consulta espontânea.

c) Estimular - o papel do professor, nesta fase, é o de Estimular as novas ideias dos alunos, sem reprimi-las. Nesse momento, não é conveniente usar o juízo crítico, pois frearia as ideias espontâneas. São três os aspectos principais que devem ser levados em conta: a motivação dos alunos no envolvimento da aprendizagem ou na realização de tarefas, instigar a comunicação e seus pensamentos e retardar o juízo crítico sobre as ideias expressadas pelos alunos.

d) Estimar - nesta etapa, as ideias geradas pelo aluno são valorizadas e avaliadas para verificar se as respostas estão de acordo com o que foi proposto. Cada professor assume certos critérios de valorização que dizem respeito à aprendizagem escolar. Porém, a avaliação deve ser feita de forma a valorizar todas as ideias, mesmo que elas não correspondam ao padrão esperado.

e) Orientar - nesta fase, do ponto de vista didático, os resultados devem ser corrigidos e o aluno deve ser reorientado. É o momento que o professor deve, juntamente com os alunos, refletir sobre as ideias que foram geradas. Novamente, o aluno é conduzido ao questionamento e à primeira etapa do processo: Problematizar.

Dentro dessa mesma ótica, o autor afirma que é possível integrar a criatividade em um projeto curricular, alinhando os objetivos, os conteúdos, a metodologia, os recursos materiais e a avaliação dessas cinco etapas. Dessa forma, a criatividade, na sua dupla vertente de capacidade e atitude, deverá estar presente em cada um desses componentes, da seguinte maneira: 
a) Deve-se colocar a criatividade, em termos de imaginação, originalidade, flexibilidade, inventividade, engenhosidade, espontaneidade, sensibilidade, tolerância, atitude questionadora, desenvolvimento de habilidades cognitivas e sociais, e aliar esses aspectos aos objetivos das disciplinas.

b) O estímulo da criatividade é dependente do domínio sobre conteúdos. Afinal quanto mais conhecimento o indivíduo possuir, maior o seu poder de criação. Ou seja, ele deve utilizar uma bibliografia vasta e conteúdos que possam agregar conhecimentos aos alunos, porém, de acordo com a carga horária disponível e com a capacidade de absorção dos indivíduos.

c) O ponto de apoio de uma metodologia criativa descansa sobre o aluno. é preciso predominar a flexibilidade, os procedimentos indiretos, a metodologia holística, as estratégias de simulação e a aprendizagem autônoma e por descobertas.

d) Os recursos materiais de aprendizagem devem ser tão variados quanto a metodologia. Um projeto criativo incorpora diferentes recursos e materiais, para poder provocar a inventividade e a divergência.

e) A avaliação dos alunos deve ser feita de forma polivalente, levando em conta as contribuições pessoais, os pontos de vista particulares, as percepções de aprendizagem e a aplicação dos conhecimentos em outras situações, casos ou problemas.

Dessa forma, o autor propõe uma "dieta educacional" na qual devem ser desenvolvidos, tanto os conhecimentos teóricos, quanto as atitudes, as competências e as habilidades sociais e cognitivas.

\subsection{O Administrador}

O papel do administrador, mesmo que ainda sem essa denominação, vem se mostrando primordial para o sucesso de organizações e equipes, desde os primeiros contatos sociais. As origens de alguns conceitos e práticas modernas de administração podem ser atribuídas a civilizações muito antigas. Salomão, um governante bíblico, dirigiu a elaboração de acordos de 
comércio, administrou programas de constituição e intermediou tratados de paz no Século X a.C. Entretanto, antes disso, já havia a necessidade de formas ou sistemas para governar o povo e também de uma figura que coordenasse e administrasse essas ações.

De acordo com Schuch Júnior (apud ANDRADE, 1997), o Conselho Federal de Educação fixou, em 1966, o primeiro currículo mínimo do Curso de Administração, sendo que tal currículo contemplava matérias de conhecimentos sistemáticos, instrumentais, de formação profissional e de cultura geral.

O Conselho Federal de Administração (2007) afirma que dentre as habilidades necessárias a um administrador estão a capacidade de planejar, de tomar decisão, de aprender, de comunicar-se, de negociar, de assumir riscos e de trabalhar em equipe.

Katz (apud BALDIN, 2003) afirma que uma administração bem-sucedida deve apoiar-se nestas três habilitações básicas: habilidade técnica, humana e conceitual.

a) Habilidade técnica - esta habilidade se refere aos conhecimentos específicos, aos métodos e técnicas referentes às funções específicas exercidas pelo administrador.

b) Habilidade humana - habilidade exercida nas relações de trabalho com os outros integrantes da equipe. Diz respeito à questão humana de se relacionar.

c) Habilidade conceitual - baseando-se no intelecto, essa habilidade tem relação com o modo com que o indivíduo vê cada parte da organização. Isso influencia diretamente na maneira como o profissional enxerga o todo, possibilitando-lhe desenvolver estratégias e visando o sucesso da empresa.

O autor defende que, na prática, torna-se difícil separar essas habilidades, pois uma depende da outra e elas costumam trabalhar em conjunto. A diferenciação faz-se apenas no âmbito da responsabilidade administrativa, dentro da organização, que definirá qual habilidade será mais utilizada.

Atualmente, os administradores trabalham com a era do conhecimento, marcada por um ambiente mutante, no qual a criatividade acaba contando como fator diferencial de sucesso para as organizações. Os agentes das empresas têm enfrentado algumas situações em que o uso da criatividade parece imprescindível. Veloso Filho (1999) cita algumas: resolver problemas rapidamente e de maneira econômica, desenvolver conhecimento, a compe- 
tição profissional, a alta concorrência, o aumento da exigência dos consumidores, a rapidez das mudanças e a velocidade das comunicações.

Dessa forma, verifica-se a necessidade de desenvolver e estimular o potencial inovador dentro dos cursos formadores de profissionais responsáveis pela gestão organizacional.

\section{Metodologia}

De acordo com o pensamento de Gil (2002), uma pesquisa pode ser definida como um procedimento racional e sistemático, que tem como objetivo procurar respostas aos problemas propostos.

Diversas classificações podem ser usadas para descrever um mesmo estudo, as quais se diferenciam de acordo com as variáveis, técnicas e instrumentos utilizados nas etapas desenvolvidas durante o processo de pesquisa.

Para atingir o objetivo a que se destina essa pesquisa, utilizou-se a seguinte metodologia: primeiramente foram avaliados os planos de ensino referentes às disciplinas oferecidas pelo CAD e posteriormente identificou-se a percepção dos alunos em relação às disciplinas. Cada uma dessas etapas será detalhada a seguir.

\subsection{Abordagem e Tipo de Estudo}

A presente pesquisa recebe diversas classificações que, de acordo com os autores utilizados como base, são: predominantemente quantitativa, descritiva - explicativa e teórica-aplicada. No que diz respeito às fontes de informações utilizadas, esta pesquisa caracteriza-se como de campo, documental, ex-post facto e participante.

Nesta pesquisa, a população em estudo concentrou-se nos alunos do Curso de Ciências da Administração da Universidade Federal de Santa Catarina, que concluíram a graduação no segundo semestre do ano de 2007.

Nos casos em que a população é pequena, Mattar (2005) aconselha a realização do censo, que consiste na avaliação do universo populacional. Esse foi o método adotado neste trabalho.

Foram abordados os alunos matriculados regularmente na disciplina de estágio supervisionado no segundo semestre de 2007, entre os dias 15 e 
24 de outubro do mesmo ano, alcançando o número de 52 respondentes, de um total de 91 alunos, ou seja, em face de motivos diversos, 39 membros da população-alvo não responderam ao questionário.

Na coleta de dados primários, que visava identificar a percepção dos alunos em relação à contribuição das disciplinas para o estímulo da criatividade, utilizou-se um questionário não disfarçado.

\subsection{Metodologia da Avaliação das Disciplinas}

Com o objetivo de verificar a contribuição das disciplinas do Curso de Administração da UFSC para o estímulo da criatividade, analisou-se, primeiramente, o plano de ensino das disciplinas oferecidas pelo $\mathrm{CAD}$, que totalizam 27 disciplinas, aproximadamente $63 \%$ do total de horas/aula propostas pelo curso. São elas: Administração I, Criação e Desenvolvimento de Novas Empresas, Teoria da Administração Geral, Organização Sistemas e Métodos, Administração da Comunicação, Administração da Informática I e II, Administração Financeira I e II, Administração de Marketing, Administração de Materiais I e II, Práticas Administrativas, Administração da Produção I e II, Administração de Recursos Humanos I e II, Processo Decisório, Pesquisa Mercadológica, Administração Orçamentária, Projeto de Estágio, Administração de Projetos, Estratégia Mercadológica, Desenvolvimento de Recursos Humanos, Direção Estratégica, Empreendedorismo e Modelos de Negociação e Estágio Supervisionado.

Para tanto, foram coletados junto à página eletrônica do Departamento de Ciências da Administração (www.cad.ufsc.br) todos os planos de ensino das disciplinas do currículo do curso ministradas pelos professores do CAD. Contudo, ressalta-se que não foram analisadas as disciplinas optativas, pelo fato de apresentarem temas distintos a cada semestre.

Primeiramente, dividiu-se o plano de ensino em dois grupos de análise: ementa e objetivos e bibliografia e metodologia de ensino. A partir dessa etapa, utilizou-se uma escala de avaliação verbal para analisar a proposta do plano de ensino das disciplinas, conforme cada uma das categorias de análise propostas por Torre (2005): Problematizar, Climatizar, Estimular, Estimar e Orientar, e de acordo com os componentes que o mesmo autor define como imprescindíveis no planejamento e na execução do processo educacional. 
A escala foi composta pelos seguintes itens: baixa contribuição para o estímulo da criatividade, razoável contribuição para o estímulo da criatividade, boa contribuição para o estímulo da criatividade e ótima contribuição para o estímulo da criatividade, não contribuição para o estímulo da criatividade. Cada um desses itens recebeu uma pontuação de 1 a 5 , de acordo com ordem que foi apresentada.

Para chegar à contribuição para o estímulo da criatividade de cada um dos aspectos avaliados, calculou-se uma média final entre as cinco categorias de análise. Do mesmo modo, para avaliar a contribuição geral de cada disciplina, chegou-se a uma média entre o resultado final obtido entre ementas, objetivos e bibliografias e metodologias. A frequência relativa foi apresentada através do número de disciplinas que apresentaram aquele resultado.

Ao avaliar a ementa, os objetivos e as bibliografias propostos nos planos de ensino das disciplinas, foram levados em consideração os seguintes aspectos abordados por Torre (2005):

a) Problematizar e Climatizar: possibilidade de imaginação e abordagem de conteúdo e de bibliografia vasta, que possibilitem ao aluno aumentar seu potencial de busca de respostas e de criação.

b) Estimular e Estimar: flexibilidade, tolerância, abertura e possibilidade de participação do aluno.

c) Orientar: preocupação com o desenvolvimento de atitude questionadora e habilidades cognitivas e sociais. Foi analisada também a natureza das disciplinas, pois, como afirma Torre (2005), alguns conteúdos naturalmente estão mais aptos ao estímulo criativo do que outros.

Por outro lado, ao avaliar a metodologia de ensino proposta pela disciplina procurou-se analisar os seguintes aspectos:

a) Problematizar e Climatizar: a combinação e a diversidade dos recursos materiais e os meios de comunicação utilizados, a combinação de materiais e ideias, bem como as atividades que estimulassem os alunos a buscarem materiais e informações extra-classe.

b) Estimular, Estimar e Orientar: desenvolvimento de atividades que visem estimular a participação do aluno, visitas de campo, estudos de caso, trabalhos em equipe, entre outros. Essas atividades também possibilitam que o professor possa orientar os alunos a partir 
de uma visão plural. Novamente foi considerada a natureza de cada disciplina.

Seguindo o mesmo modelo utilizado para avaliação do plano de ensino, os alunos analisaram cada uma das disciplinas do curso oferecidas pelo CAD como um todo, de acordo com o modelo proposto por Torre (2005). Para isso, utilizaram escala similar à da avaliação do plano de ensino que contemplava os seguintes itens: baixa contribuição para o estímulo da criatividade, razoável contribuição para o estímulo da criatividade, boa contribuição para o estímulo da criatividade, ótima contribuição para o estímulo da criatividade, não contribuição para o estímulo da criatividade, não cursei essa disciplina e não me recordo. Cada um desses itens recebeu a pontuação de 1 a 7, de acordo com essa mesma ordem.

Para calcular a contribuição das cinco etapas de cada disciplina, chegou-se a uma média entre todas as respostas obtidas na pesquisa junto aos alunos, para cada variável de análise. O resultado final sobre a contribuição de cada disciplina para o estímulo da criatividade foi obtido através da média entre essas cinco etapas. Por fim, para chegar a um resultado sobre a contribuição final do curso, calculou-se a média entre os resultados obtidos pelas disciplinas, segundo a percepção dos alunos.

\section{Resultados}

Com o intuito de verificar a contribuição do Curso e Administração da UFSC para o estímulo da criatividade nos alunos egressos do segundo semestre de 2007, procurou-se sistematizar a pesquisa em duas etapas: análise do plano de ensino das disciplinas do Departamento de Ciencias da Administração, que foi realizada pela pesquisadora, e identificação da percepção dos graduandos em relação à contribuição das disciplinas para o estímulo da criatividade.

$\mathrm{Na}$ apresentação das informações obtidas, foi elaborado um comparativo entre o que foi analisado nos planos de ensino (realizada pelo pesquisador) e a avaliação realizada pelos alunos. Primeiramente, serão apresentados os resultados de acordo com cada uma das categorias de análise utilizadas como base: Problematizar, Climatizar, Estimular, Estimar e Orientar. Posteriormente, será apresentado um resultado final sobre a contribuição das disciplinas para o estímulo da criatividade, segundo as duas óticas. 
Na sequência, serão demonstrados os resultados obtidos a partir da tabulação dos dados referentes aos objetivos específicos desta pesquisa.

Ao analisar as frequências relativas entre as duas perspectivas - Planos de Ensino e Percepção dos alunos - verificou-se que na categoria Problematizar houve certa discrepância entre as duas óticas. Enquanto a avaliação dos planos de ensino aponta para um estímulo da criatividade ótimo $(37,04 \%)$, a percepção dos alunos demonstra uma contribuição entre razoável e boa $(66,67 \%)$ para o estímulo da criatividade nessa categoria.

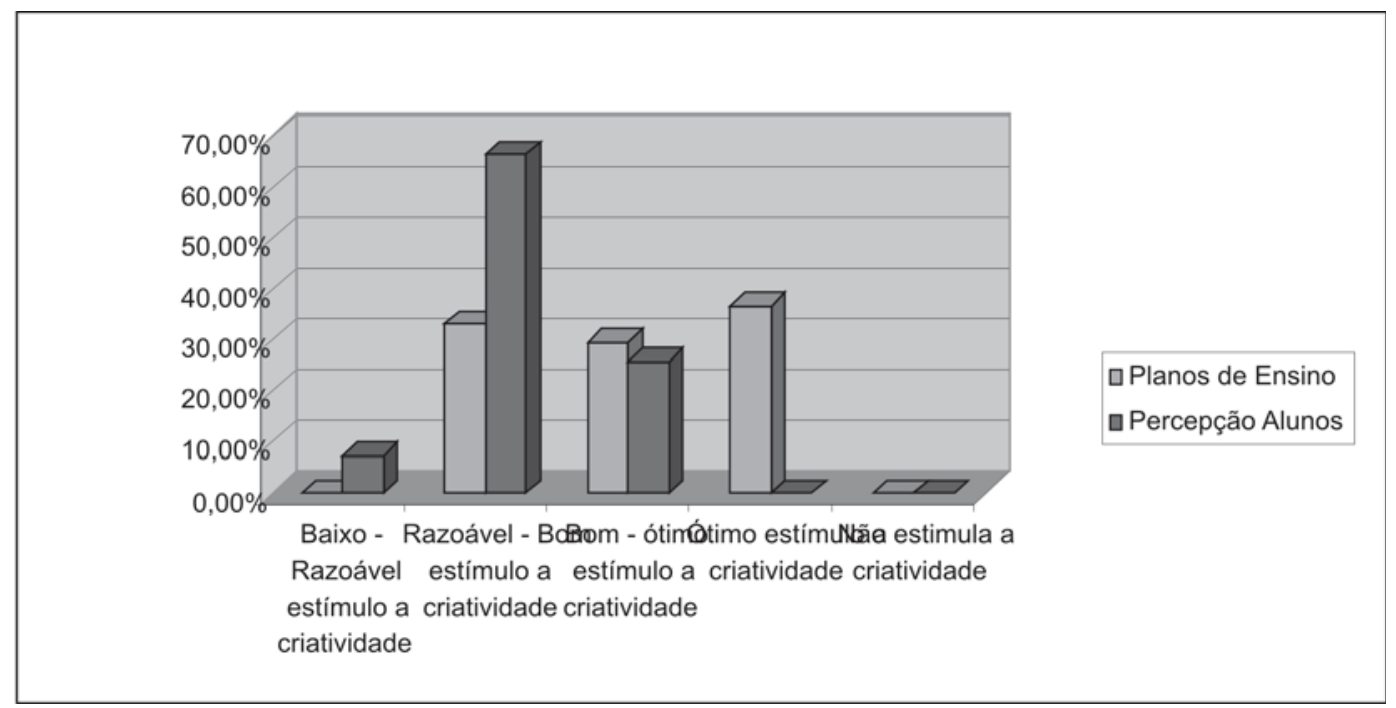

Gráfico 1: Problematizar - avaliação das disciplinas X percepção dos alunos.

Fonte: Dados primários.

A avaliação das disciplinas, na etapa Climatizar, também demonstra uma diferença entre o que foi avaliado nos planos de ensino e o que foi analisado pelos alunos. Na avaliação dos planos de ensino, a maioria das disciplinas apresentou contribuição ótima para o estímulo da criatividade (59,29\%), enquanto que na ótica dos alunos, a maioria das disciplinas $(66,67 \%)$ apresenta contribuição entre razoável e boa.

Ao analisar o Gráfico 2, verificou-se que, na etapa Estimular, a maioria das disciplinas apresenta entre boa e ótima contribuição $(88,89 \%)$ para o estímulo da criatividade. Todavia, na avaliação dos alunos, a maior parte das disciplinas apresentou contribuição entre razoável e boa $(59,26 \%)$. 


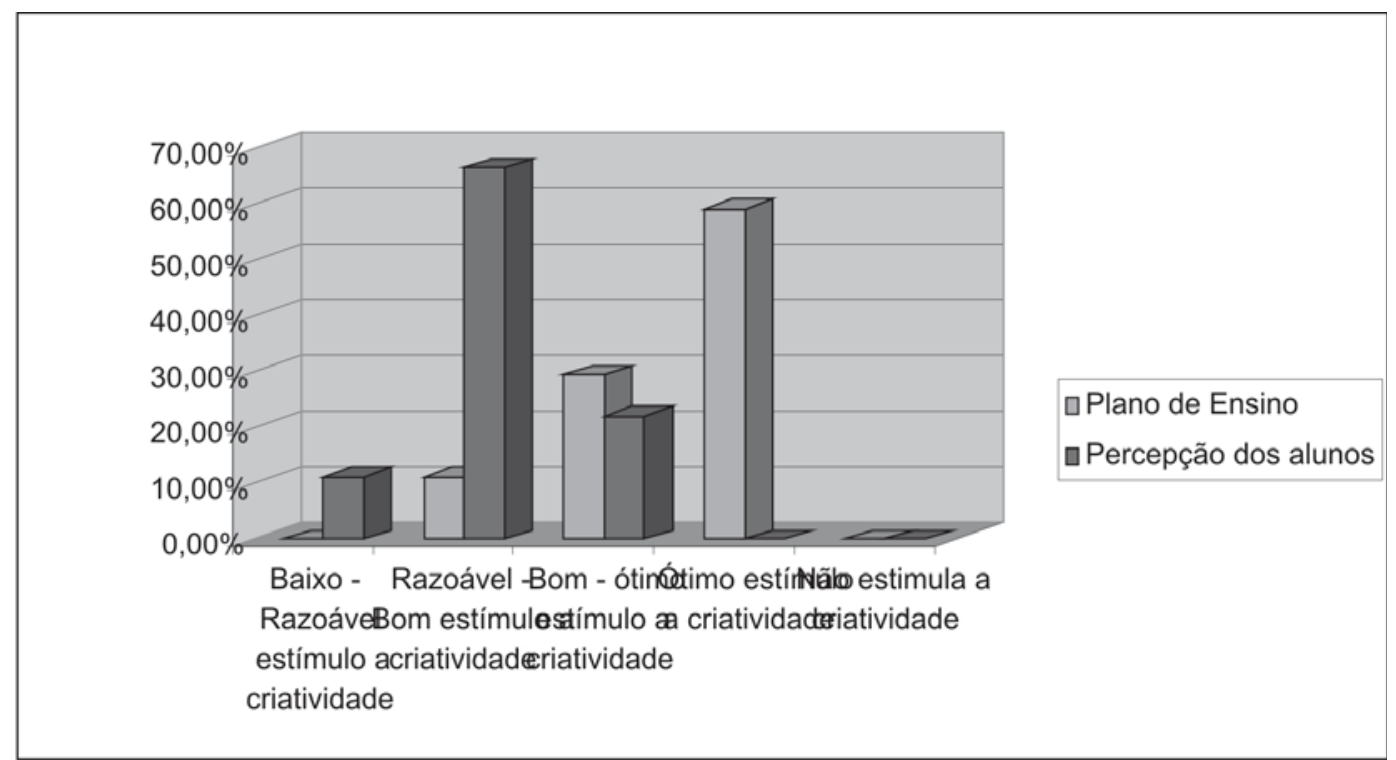

Gráfico 2: Climatizar - avaliação das disciplinas X percepção dos alunos. Fonte: Dados primários.

Na categoria Estimar, os resultados da avaliação dos planos de ensino se mostraram bastante divididos entre as categorias: baixo a razoável estímulo $(29,63 \%)$, razoável a bom estímulo $(29,63 \%)$ e bom a ótimo estímulo $(37,04 \%)$.

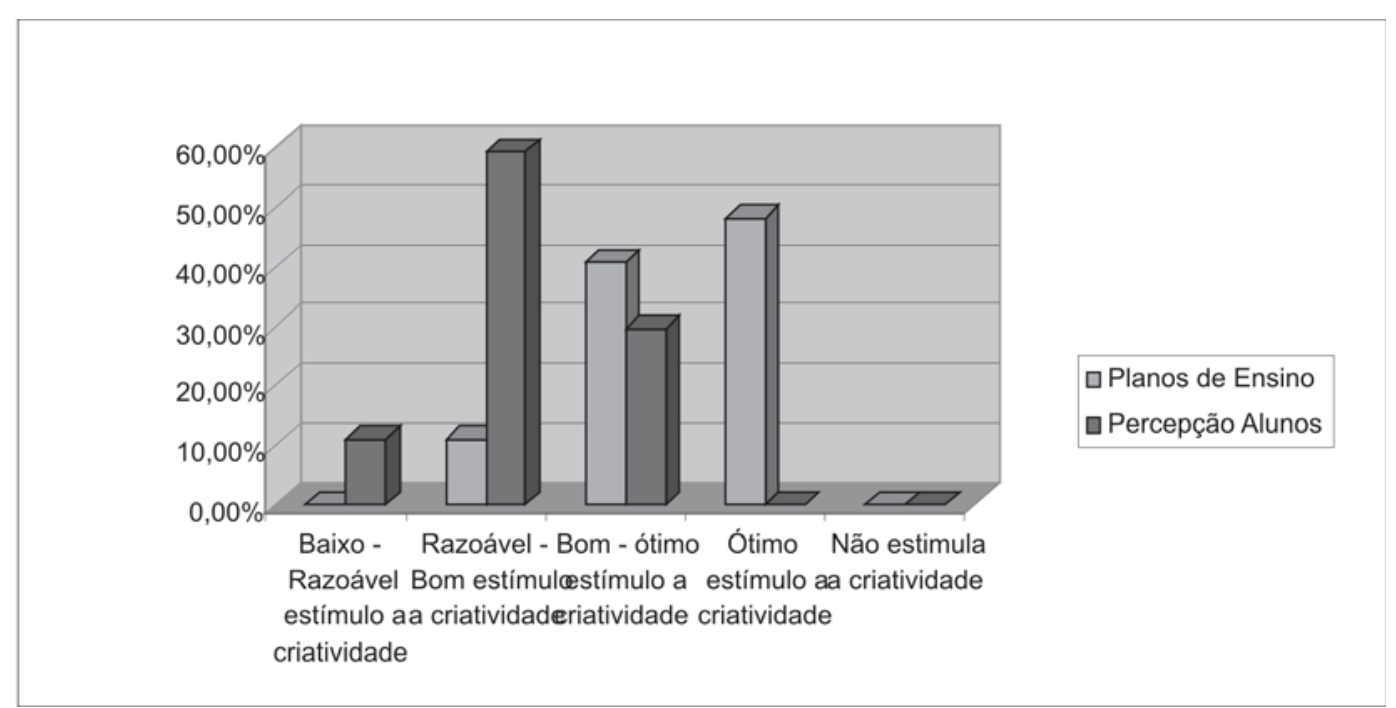

Gráfico 3: Estimular - avaliação das disciplinas X percepção dos alunos.

Fonte: Dados primários. 
Por outro lado, na percepção dos alunos, a maioria das disciplinas $(66,67 \%)$ apresenta entre razoável e boa contribuição para o estímulo da criatividade.

Ao analisar o Gráfico 5 apresentado a seguir, verifica-se que, na avaliação das disciplinas, a maior parte apresenta contribuição entre boa e ótima $(85,19 \%)$, enquanto na percepção dos alunos, a maioria apresenta contribuição entre razoável e boa (70,37\%), na etapa Orientar.

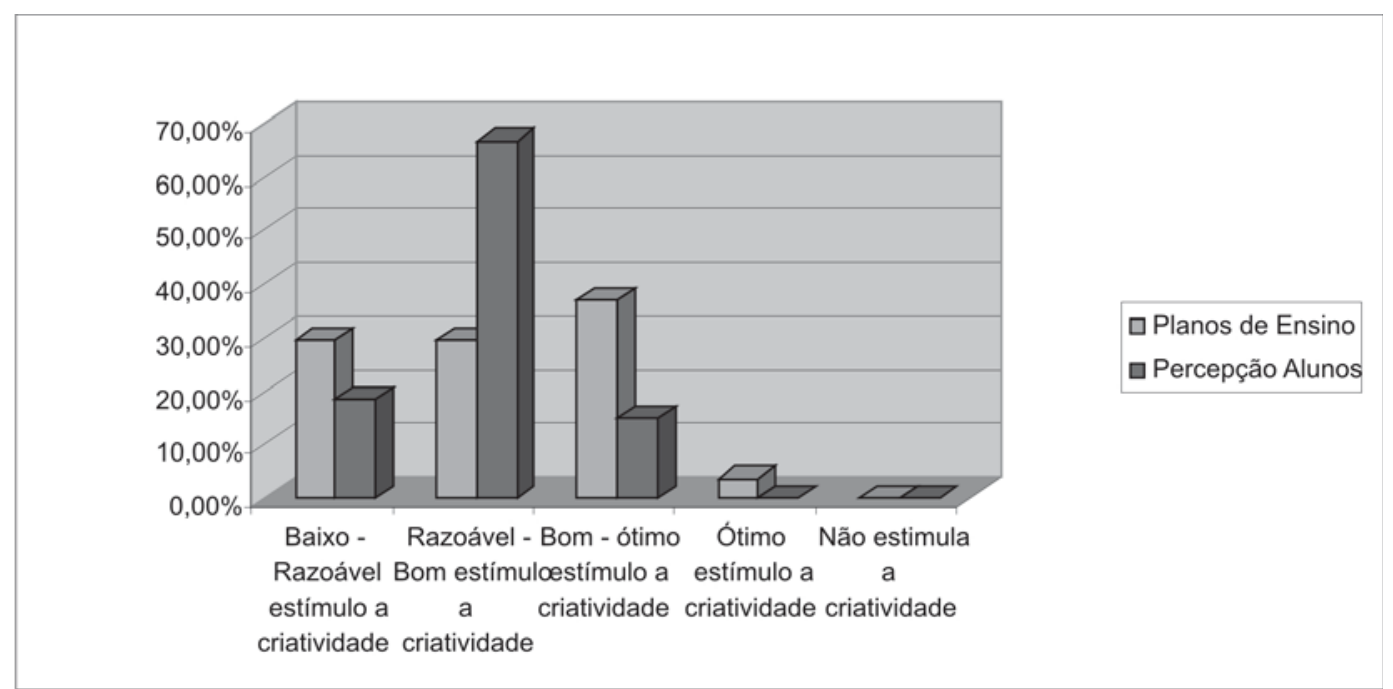

Gráfico 4: Estimular - avaliação das disciplinas X percepção dos alunos. Fonte: Dados primários

Ao analisar a contribuição geral das disciplinas, resultante da média entre as cinco etapas, identificou-se que, com relação ao que é demonstrado no plano de ensino, a maioria das disciplinas $(62,96 \%)$ apresenta uma contribuição entre boa e ótima para o estímulo da criatividade. Porém, o que foi percebido pelos alunos egressos do segundo semestre de 2007 é que a maioria das disciplinas $(62,96 \%)$ apresenta uma contribuição entre razoável e boa para o estímulo da criatividade. 


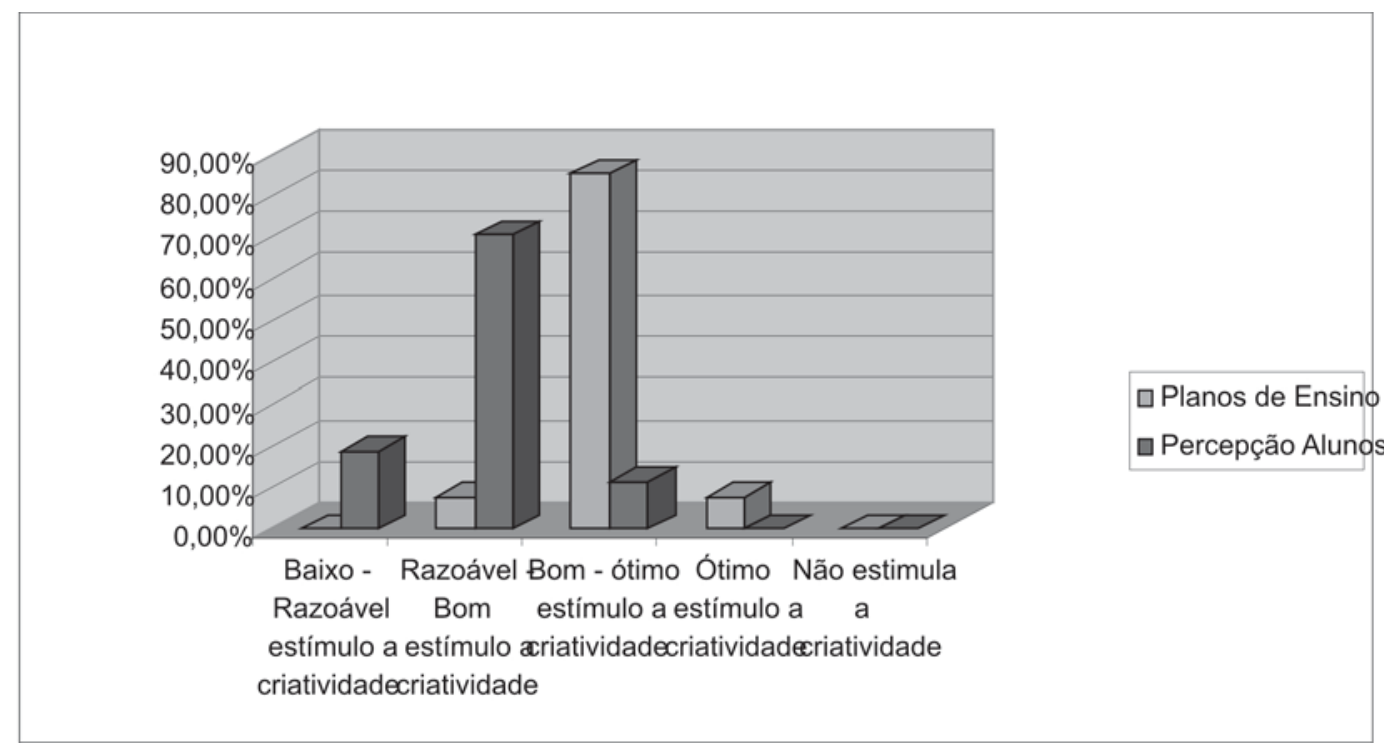

Gráfico 5: Orientar - avaliação das disciplinas X percepção dos alunos. Fonte: Dados primários.

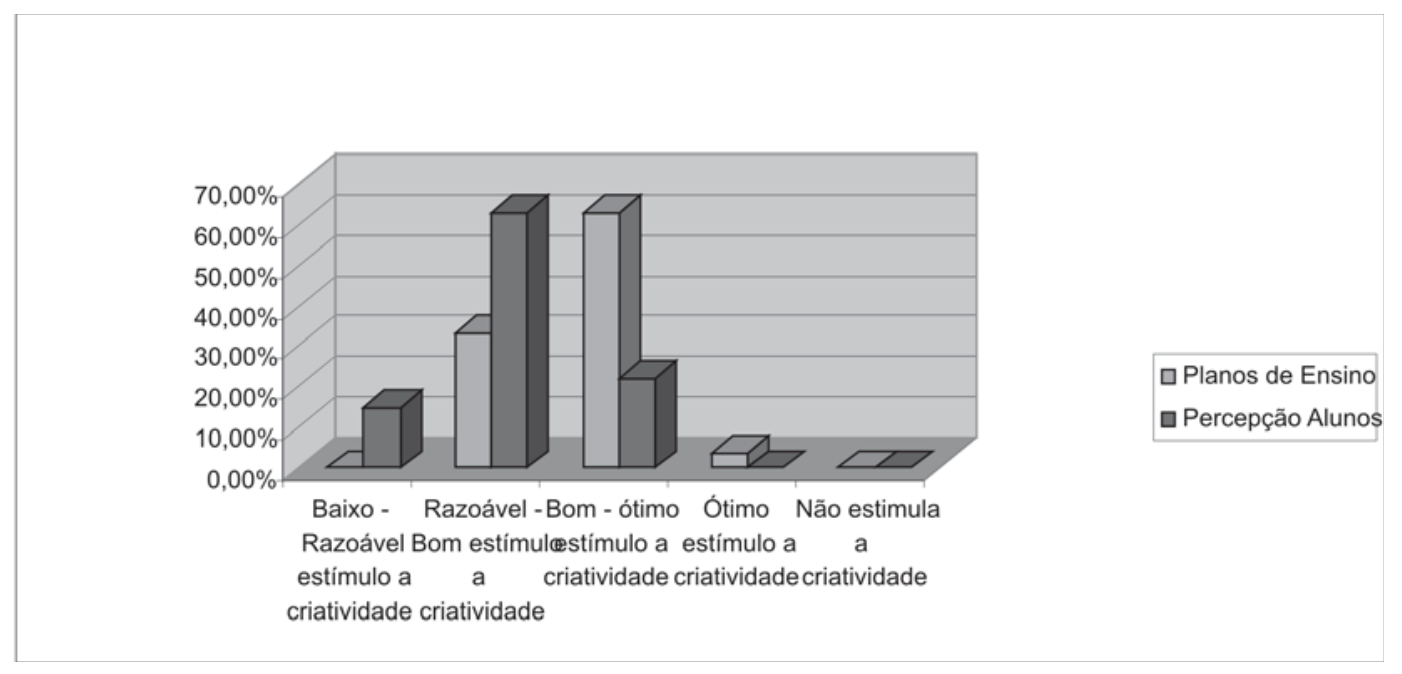

Gráfico 6: Contribuição para o estímulo da criatividade - avaliação das disciplinas X percepção dos alunos.

Fonte: Dados primários. 


\section{Considerações Finais e Recomendações}

O crescente advento da criatividade em ambientes organizacionais, nas últimas décadas, despertou em estudiosos da área o interesse pelo estudo de aspectos que estimulem o poder de criação do ser humano. Nesse processo, já é comprovado que tanto a família, quanto a escola exercem uma papel de extrema importância. Afinal, essas duas instituições são responsáveis pela formação do indivíduo e podem afetar negativamente ou positivamente no desenvolvimento do poder criativo.

Em face ao ambiente mutante vivido atualmente, exige-se dos gestores mais do que simplesmente conhecimentos adquiridos na academia ou na prática, exige-se também que eles tenham capacidade de empreender e de serem profissionais ágeis, inovadores e criativos.

A fim de auxiliar nesse desenvolvimento, o presente artigo foi delineado a partir do objetivo de verificar a contribuição do Curso de Administração da Universidade Federal de Santa Catarina, para o estímulo da criatividade dos alunos egressos do segundo semestre de 2007.

Diante dos objetivos pretendidos com a pesquisa, pôde-se identificar a contribuição das disciplinas para o estímulo do potencial criativo dos alunos. Constatou-se certa discrepância entre o que é pretendido pelas disciplinas (planos de ensino) e o que é percebido pelos alunos em sala de aula. Por fim, chegou-se a uma conclusão sobre a real contribuição do curso para o estímulo da criatividade.

Ao traçar um comparativo entre o que foi avaliado nos planos de ensino e a percepção dos alunos, chegou-se a resultados de extrema relevância, os quais demonstram uma discrepância entre a teoria (planos de ensino) e a prática (percepção dos alunos). Na categoria Problematizar, segundo a avaliação dos planos de ensino, a contribuição das disciplinas para o estímulo da criatividade dividiu-se entre as faixas razoável a boa (33,33\%), boa e ótima $(66,67 \%)$ e ótima contribuição $(37,04 \%)$. Segundo a análise dos alunos, a maior parte das disciplinas apresenta entre razoável a bom estímulo $(66,67 \%)$ contra $25,93 \%$ que se enquadram na faixa bom a ótimo estímulo da criatividade.

Na categoria Climatizar, a diferença entre as avaliações foi ainda mais acentuada. Enquanto a análise dos planos de ensino aponta a contribuição das disciplinas para o estímulo da criatividade como ótima $(59,26 \%)$, a per- 
cepção dos alunos indica que a real contribuição das mesmas está entre razoável e boa $(66,67 \%)$.

A etapa Estimular os planos de ensino das disciplinas foi avaliada com uma contribuição entre boa e ótima $(88,89 \%)$, enquanto que o percebido pelos alunos foi uma contribuição das disciplinas oferecidas pelo CAD, na maior parte, entre razoável e boa $(59,26 \%)$.

A categoria Estimar apresentou, em seus resultados, uma contribuição das disciplinas para o estímulo da criatividade, na faixa baixo a razoável de $29,63 \%$ na avaliação dos planos de ensino contra $18,52 \%$ na percepção dos alunos; na faixa razoável a boa de $29,63 \%$ na avaliação dos planos de ensino contra $66,67 \%$ na percepção dos alunos; e na faixa boa à ótima $37,04 \%$ na avaliação dos planos de ensino contra $14,81 \%$ na avaliação dos alunos.

No comparativo da última categoria, Orientar apresentou resultados de extrema relevância. A maior parte das disciplinas, na avaliação dos planos de ensino, apresentou contribuição para o estímulo da criatividade entre boa e ótima $(85,19 \%)$; na percepção dos alunos, essa categoria foi a que apresentou o pior resultado. $18,52 \%$ das disciplinas apresentaram contribuição entre baixa e razoável e 70,37\% apresentaram contribuição entre razoável e boa. Esse aspecto chama atenção, visto que a etapa Orientar é uma das categorias mais importantes no processo educacional. Tal ponto fora atingido, talvez pela inflexibilidade de algumas disciplinas, que acabam por desmerecer algumas das ideias geradas pelos alunos, por se considerar fora dos padrões de resposta.

Por fim, tendo em vista o objetivo principal desta pesquisa - analisar a contribuição do Curso de Administração da UFSC para o estímulo da criatividade nos alunos egressos dos segundo semestre de 2007 - chegou-se a um resultado entre razoável e bom estímulo, o qual representa a percepção dos alunos quanto ao desempenho das disciplinas.

Com base nos resultados dessa pesquisa e no que é proposto por Torre (2005), recomenda-se uma revisão dos planos de ensino, a fim de identificar pontos a serem melhorados, com o intuito de desenvolver o potencial indagador, crítico, além de habilidades, atitudes e competências relacionadas à capacidade de criação dos alunos.

É também de extrema importância que os responsáveis pelas disciplinas façam um alinhamento entre a proposta das mesmas e o que é desenvolvido em sala de aula, tomando como base cada uma das categorias analisadas. Com isso, poderiam desenvolver em todas as disciplinas uma real con- 
tribuição para o estímulo da criatividade. Esse aprimoramento pode ser feito através da criação de uma comissão, formada por alunos e professores, à qual caberia analisar os resultados apresentados neste trabalho, bem como o currículo do curso.

Objetivando uma incessante procura pelo aperfeiçoamento acadêmico, espera-se que, a partir desse trabalho, os responsáveis pelas disciplinas oferecidas pelo CAD, referentes ao Curso de Administração, façam uma análise dos resultados obtidos e, depois, promovam uma autoavaliação em relação às disciplinas ministradas e que isso permita com que façam um alinhamento entre a proposta de ensino das disciplinas e a sua postura em sala de aula.

Afinal, o Curso de Administração da UFSC tem por objetivo formar profissionais capazes e competentes. Por isso, precisa cumprir com o que se destina: preparar um profissional criativo, com capacidade empreendedora, capaz de se integrar facilmente aos objetivos de uma organização e coordenar as diferentes áreas organizacionais e as estratégias operacionais.

Ademais, outros estudos podem ser realizados a partir deste, como a identificação das percepções do corpo docente ou então outros elementos que contribuem para o estímulo da criatividade.

\title{
Criativity in Education: a case study of the Course Management of UFSC - Universidade Federal de Santa Catarina.
}

\begin{abstract}
It's indisputable the importance of the creativity in the knowledge society In this process, it has been proved that neither the family nor the school has a role of extreme importance. In face of this, the present article aimed to analyze the contribution of the course Administration of University Federal Santa Catarina for the stimulus of creativity. The study was designed from the assessment of the education plans of the disciplines offered by the CAD and the analysis of the perception of the students Regarding the methodology used, the study was characterized as: qualitative, exploratory, descriptive, theoretically applied with field study, documentary, ex-post facto and participant and applied theoretician; Among the results achieved was identified, the discrepancy between the education plans of the disciplines (theory) and the perception of the students (practice), and a real contribution of the course for the stimulus of creativity between reasonable and good.
\end{abstract}


Key-words: Creativity. Innovation. Education process.

\section{REFERÊNCIAS}

ALENCAR, E. M. L. S. de. A gerência da criatividade: abrindo as janelas para a criatividade pessoal e nas organizações. São Paulo: Makron Books, 1996.

AMABILE, T. M. Como não matar a criatividade. Revista HSM Management. São Paulo, n. 12, jan./fev. 1999. p. 110-116.

ANDRADE, R. O. B. de. História e perspectiva dos cursos de Administração do Brasil. Anais do II Seminário Nacional sobre qualidade e avaliação dos cursos de Administração. Vitória. De 27 a 29 de agosto de 1997.

BALDIN, C. O administrador da nova era: as habilidades que lhe são necessárias. Caderno da Administração. Marinhgá, v. 9, n.1, p. 131-148, jan./jul. 2003.

BONO, E. de. Criatividade como recurso. Revista HSM Management. São Paulo, p. 66-73, mar./abr. 2000.

CARR, C. O poder competitivo da criatividade. São Paulo: Makron Books, 1997.

CFA - Conselho Federal de Administração. Institucional. Disponível em: $<$ www.cfa.org.br>. Acesso em: 17 jun 2009.

DE MASI, D. Criatividade e grupos criativos: fantasia e concretude. Tradução de Lea Manzi e Yadyr Figueiredo. Rio de Janeiro: Sextante, 2005.

DRUCKER, P. F. A profissão do administrador. São Paulo: Pioneira, 1994.

DUARTE, M. O livro das invenções. São Paulo: Companhia das Letras, 1997.

GIL, A. C. Como elaborar projetos de pesquisa. 4. ed. São Paulo: Atlas, 2002.

MARTÍNEZ, A. M. Criatividade, personalidade e educação. Tradução de Mayra Pinto. São Paulo: Papirus, 1997. 
MATTAR, F. N. Pesquisa de Marketing, v. 1 e 2, São Paulo: Atlas, 2005.

PAROLIN, S. R. H. A perspectiva dos líderes diante da gestão da criatividade em empresas da região metropolitana de Curitiba - PR. Dissertação (Mestrado em Administração). Porto Alegre: Universidade Federal do Rio Grande do Sul, 2001.

RAY, M.; MEYERS, R. Criatividade nos negócios. Rio de Janeiro: Record, 1996.

SEBRAE - Serviço Brasileiro de Apoio às Micro e Pequenas Empresas. Criação e desenvolvimento de novas empresas. 2002. Disponível em: < http:// www.sebrae.com.br>. Acesso em: 17 jun. 2009.

STONER, J. A. F; FREEMAN, R. E. Administração. 5. ed. Rio de Janeiro: Prentice-Hall do Brasil, 1995.

TERRA, J. C. C. Gestão do conhecimento: o grande desafio empresarial uma abordagem baseada no aprendizado e na criatividade. São Paulo: Negócio Editora, 2000.

TORRANCE, E. P. Criatividade, medidas, testes e avaliações. São Paulo: Ibrasa, 1974.

TORRE, S. de la. Dialogando com a Criatividade: da identificação à criatividade paradoxal. Tradução de Cristina Mendes Rodríguez. São Paulo: Madras, 2005.

VELOSO FILHO, F. Considerações sobre a criatividade nas organizações. Revista de Administração Pública. Rio de Janeiro, v. 33, n. 2, mar./abr. 1999. p. $128-145$.

Vergara, S. M. Projetos e Relatórios de Pesquisa em Administração. São Paulo: Atlas, 1997.

VIRGUlim, A. M. R.; FLEITH, D. S.; PEREIRA, M. S. N. Toc, Toc, Plim, Plim: lidando com as emoções e brincando com os pensamentos através da criatividade. 5. ed. Campinas, SP: Papirus, 2003.

WECHSLER, S. M. Criatividade: descobrindo e encorajando. São Paulo: Editora Psy, 1998. 